\title{
REVISÃO
}

\section{Culturas iniciadoras de fermentação em vinhos}

\section{SANTOS, Débora dos; ${ }^{\star}$ GELINSKI, Jane Mary Lafayette Neves *ᄎ}

\section{Resumo}

Este artigo apresenta uma revisão bibliográfica a respeito das culturas iniciadoras de fermentação em vinhos. Fez-se uma abordagem a partir dos últimos cinco anos de pesquisa em temáticas pertinentes às áreas de Microbiologia, Biotecnologia, Ciências de Alimentos e Enologia com culturas iniciadoras. Foram revisados os processos de fermentação alcoólica, maloláctica, mista, bem como os métodos de estudo, com destaque para a Biotecnologia e as perspectivas de estudos. Palavras-chave: Culturas iniciadoras. Fermentação alcoólica. Fermentação maloláctica. Culturas mistas. Biotecnologia.

\section{Wine starters cultures}

Abstract

This article presents a review about wine starters cultures. It makes a report in recent 5 years of researches about starters cultures in the follow areas: Microbiology, Biotechnology, Food Science and Enology. It was reviewed winemaking fermentations and mixed cultures as well as methodologies in the domain of Biotechnological data and the studies perpectives.

Keywords: Starter culture. Alcoholic Fermentation. Malolactic Fermentantion. Mixed Culture. Biotechnology.

\footnotetext{
* Mestre em Educação Científica e Tecnológica pela Universidade Federal de Santa Catarina; Especialista em Microbiologia pela Universidade do Oeste de Santa Catarina; d_san22@hotmail.com

** Doutora em Ciência dos Alimentos pela Universidade de São Paulo; Mestre em Genética pela Universidade Federal do Rio Grande do Sul; professora pesquisadora da Unoesc; jgelinski@yahoo.com.br
} 


\section{INTRODUÇÃO}

Culturas starters ou culturas iniciadoras de fermentação consistem na seleção de microrganismos de alimentos com atividade metabólica estável e conhecida, portadores de outras características usadas para produzir alimentos e bebidas fermentadas de aparência, corpo, textura e sabor desejáveis (RAY, 2004). Atualmente esse termo abrange as formas de microrganismos fermentadores inoculados ao meio também com função protetora contra espécies contaminantes (GERBAUX et al., 2009).

O processo fermentativo em vinhos é caracterizado por uma transformação complexa do mosto da uva, pela presença de fungos filamentosos, leveduras e bactérias ácido lácticas que utilizam os açúcares fermentescíveis e outros compostos derivados a partir desse processo para elaborar o vinho. Apesar de o mosto ser um meio bastante rico em nutrientes, seu pH ácido e elevado conteúdo de açúcares exercem pressão seletiva sobre esses microrganismos e somente poucas espécies são capazes de crescer no meio. Entre esses microrganismos, as leveduras são as principais responsáveis dessa transformação bioquímica, por realizar a fermentação alcoólica (KÖNIG; UNDEN; FRÖHLICH, 2009).

A fermentação alcoólica, do ponto de vista prático, é conhecida pela humanidade desde os tempos mais remotos. Há relatos bíblicos que contam da elaboração do vinho no período de Noé. Entretanto, o conhecimento científico das fermentações aumentou de modo significativo após as descobertas de Louis Pasteur, em meados do século XVII (AMARANTE, 2005). A reação química do desdobramento de uma molécula de glicose em álcool e anidrido carbônico com liberação de calor, atualmente, é visto como a simples manifestação exteriorizada do processo nutricional das leveduras quando em meio anaeróbio.

Com os avanços científico e tecnológico, um fenômeno ocorrido nos vinhos de todo o mundo, antes confundido com uma fermentação alcoólica secundária, passou a ser melhor conhecido e estudado. Da observação da redução da acidez do mosto por um aumento de ácido láctico com decorrente diminuição de ácido málico, por meio de técnica de cromatografia somado a exames microscópicos, revelou-se a presença de bactérias ácido-lácticas. A estes microrganismos foi atribuído o papel fundamental na então denominada fermentação maloláctica ou secundária (KÖNIG; UNDEN; FRÖHLICH, 2009).

Atualmente, sabe-se que as fermentações alcoólica e maloláctica são grande parte do sucesso dos processos de vinificações. Neste sentido, muitos estudos são realizados ao longo de anos para se tentar compreender e avaliar os microrganismos envolvidos na elaboração do vinho, aspectos de sua biologia e suas capacidades de interação com o meio e com as outras espécies. O somatório desses achados vem contribuindo para que os processos de fermentações inoculadas fiquem cada vez mais eficientes e produzam vinhos com qualidade sensorial aceitável e seguramente reproduzível (AMARANTE, 2005).

Evidência, Joaçaba v. 8 n. 1-2, p. 57-84, janeiro/dezembro 2008 
Culturas iniciadoras de fermentação em vinhos

Em contrapartida, em certas regiões tradicionais da Europa, há quem defenda que a ciência não deveria intervir em relação o processo fermentativo em vinhos, deixando as fermentações ocorrerem de forma natural. Contudo, o problema da dependência das fermentações espontâneas em escala comercial está na dificuldade de se predizer e reproduzir as mesmas características do produto acabado (AMARANTE, 2005). O número e a diversidade de microrganismos presentes, a variedade e estado da uva, as práticas vitivinícolas empregadas e outros fatores somados, são os pontos que hoje a Ciência trabalha no sentido de assegurar a padronização e a qualidade do vinho comercial.

Considerando-se os avanços biotecnológicos recentes, o uso das culturas iniciadoras de fermentação fazem uma grande revolução na indústria de elaboração de vinhos. Muitos microrganismos antes presentes nas fermentações espontâneas, seja vindo no interior da fruta, seja advindo de lesões na casca da uva causadas por insetos e pássaros, ou mesmo, em razão das práticas vitivinícolas, puderam ser isolados e avaliados de diversas formas. A partir disso, sua interação no mosto e em meios sintéticos simulados desenvolvidos em laboratório vêm fornecendo melhores resultados à indústria vinícola (KÖNIG; UNDEN; FRÖHLICH, 2009).

No entanto, nem sempre as espécies selecionadas de ambientes naturais para iniciarem um processo fermentativo portam todas as características desejáveis para o sucesso da fermentação. Desse modo, tem fundamento o desenrolar de um longo trabalho dos cientistas para estudar os aspectos pormenorizados de microrganismos fermentadores e de novas tecnologias de estudo com suas cepas.

Este estudo traz um importante resumo das abordagens recentes em relação culturas iniciadoras de fermentação em vinhos, publicadas em $\operatorname{artigos}^{1}$ de periódicos das áreas de Microbiologia, Biotecnologia, Ciências de Alimentos e Enologia, nos últimos cinco anos (jan./2005 a dez./2009).

O objetivo é revisar o tema das culturas iniciadoras em vinhos, reunindo as novas informações e dando continuidade a outras revisões que vêm se fazendo sobre esse assunto. Certamente, este trabalho servirá como fonte de consulta para muitos iniciantes da área, pesquisadores acadêmicos, enólogos e produtores de vinho interessados nos avanços biotecnológicos relativos às culturas iniciadoras.

\subsection{ESTUDOS DE REVISÃO ANTERIORES}

Com relação a outras revisões na literatura, trabalhos a respeito das preparações de leveduras secas inativas (IDY), amplamente utilizadas na indústria vinícola, mobilizam tanto progressos para as pesquisas da fermentação alcoólica quanto da fermentação maloláctica. As IDY em conjunto com culturas iniciadoras, geram propriedades organolépticas requeridas aos vinhos e têm efeitos sobre a segurança do processo, prevenindo, entre outros, o aparecimento da ocratoxina A (POZO-BAYÓN; ANDÚJAR-ORTIZ; MORENO-ARRIBAS, 2009). 
Em outro estudo, as revisões sobre formas de preparação de leveduras secas ativas, as culturas iniciadoras de fermentação alcoólica propriamente, encontram-se publicadas no livro soviético Sovremennye preparativnye formy drozhzhey dlya vinodeliya de Martinenko (2006). Recentemente, a existência dessa publicação foi comunicada por Naumov (2009). Embora o livro seja de relevância incidente quanto à presente pesquisa, uma vez que trata da revisão e crítica de uma coleção de mais de 400 fontes no tema das culturas de fermentação alcoólica, a língua de origem se torna uma barreira ao acesso desse tipo de conhecimento.

Uma pesquisa de revisão referente ao tema trata da explotação do potencial de "lees" ou sedimentos-mãe: resíduos que se acumulam no fundo do recipiente de vinificação após a fermentação alcoólica, durante a estocagem de vinhos, ou, sob tratamentos autorizados. O sedimento-mãe pode ser muito útil, de acordo com os estudos levantados por Pérez-Serradilla e Castro (2008), uma vez que podem desempenhar de modo natural funções para a melhoria, qualidade e segurança de vinhos e indiretamente ter ação sobre as culturas fermentadoras e seus compostos requeridos e excretados no meio onde se processa a vinificação.

Em se tratando de culturas iniciadoras de fermentação maloláctica, os primeiros estudos de sucesso apontavam para uma espécie: Leuconostoc oenos. A partir disso, muitas publicações concentraram esforços para desvendar a bioenergética, a produtividade, as condições de crescimento mediante fatores de estresse, além de realizar análises sensoriais dos produtos finais gerados por esse microrganismo (VERSARI; PARPINELLO; CATTANEO, 1999).

Não tardou até que os cientistas pudessem identificar um membro da família Leuconostocaceae, entre as cepas com as melhores características para realizar a fermentação maloláctica em vinhos: Oenococcus oeni. Esta bactéria ácido-láctica vem sendo amplamente estudada abordando: seu uso como fonte potencial de enzimas para a vinificação (MATTHEWS et al., 2004); análise genômica de O. oeni PSU-1 e tópicos selecionados acerca de seu metabolismo de crescimento (MILLS et al., 2005); e bases moleculares de resposta a estresse (SPANO; MASSA, 2006).

Com a descoberta e caracterização de O. oeni, microrganismo-chave da fermentação maloláctica, as interações com a levedura da fermentação alcoólica, Saccharomyces cerevisiae, foram também objetos de estudo dos cientistas. A revisão de Alexandre et al. (2004) sublinha os conhecimentos correntes e as perspectivas de estudo relativas aos tópicos: inibição estimulação da bactéria maloláctica pela levedura; inibição da levedura pela bactéria maloláctica; influência das práticas de elaboração de vinho sobre a interação levedura-bactéria; e, ainda, aponta os métodos para o estudo da interação de bactérias e leveduras.

Baseado em estudos de revisão, o presente artigo prosseguirá revisando os temas relativos às culturas iniciadoras de fermentação alcoólica e maloláctica, o uso desses microrganismos como culturas mistas em inoculações sequenciais e inclusive as interações levedura-bactéria de fermentações

Evidência, Joaçaba v. 8 n. 1-2, p. 57-84, janeiro/dezembro 2008 
Culturas iniciadoras de fermentação em vinhos

simultâneas, os métodos de estudo de culturas iniciadoras, com ênfase na biotecnologia e, por último, apontará tendências a esse respeito.

\section{CULTURAS INICIADORAS DE FERMENTAÇÃO}

Iniciando o presente estudo, os temas tratados na revisão bibliográfica abordarão as culturas iniciadoras especificamente as etapas da fermentação dos vinhos, alcoólica e maloláctica. Também serão abordados os trabalhos que estudam as culturas mistas, isto é, aquelas culturas compostas de mais de um tipo de microrganismo selecionado, adicionadas ao vinho, independentemente da sua etapa de fermentação.

\subsection{FERMENTAÇÃO ALCOÓLICA}

A utilização de culturas iniciadoras de fermentação alcoólica em vinhos é iniciada com a inoculação do cultivo puro de levedura selecionada no mosto. Esta inoculação serve para cumprir as três objetivos principais das indústrias vinícolas: garantir um rápido início da fermentação, garantir a continuidade do processo fermentativo; assegurar a reprodutibilidade da elaboração do vinho mantendo a qualidade padrão. Para tanto, é necessário que as leveduras inoculadas cresçam ativamente impondo-se sobre as espécies de leveduras selvagens presentes no mosto (KÖNIG; UNDEN; FRÖHLICH, 2009).

Estudos realizados com culturas iniciadoras de fermentação alcoólica dos últimos cinco anos, para a fermentação de diversos tipos de vinhos, têm sido empregados com êxito pelos pesquisadores. Os impactos de estresse do meio nas condições iniciais da fermentação (conteúdo alto de açúcares glicose, frutose - alta acidez do fruto, outras condições físico-químicas adversas) sugerem que a seleção das cepas de leveduras com as melhores características para o início da vinificação, de acordo com Pulvirenti et al. (2009), devem seguir o acompanhamento de três fases: 1) A seleção das leveduras que dominam a fermentação espontânea; 2) A seleção entre as cepas dominantes daquelas que mostram as melhores características tecnológicas; 3) A seleção final entre as boas cepas tecnológicas daquelas que geram tratos qualitativos desejáveis. Nesse sentido, convém apresentar os trabalhos que traçam um paralelo das fermentações espontâneas com as fermentações inoculadas, na base das respostas a estresses e na performance fermentativa, metabolismo de crescimento e biodiversidade das cepas.

Nas fermentações alcoólicas, a utilização de frutose pode ser crítica para a manutenção da alta taxa de fermentação final. Em ambos os tipos de fermentação (espontânea e inoculada), a glicose é o açúcar preferencial, entretanto, em testes realizados com leveduras Saccharomyces e seus híbridos, inoculadas à baixa temperatura $\left(12^{\circ} \mathrm{C}\right)$, o consumo de frutose por estas cepas no início da fermentação foi mais intenso que à alta temperatura $\left(28^{\circ} \mathrm{C}\right)$ (TRONCHONI et al., 2009). Uma investigação a 
respeito da base molecular de utilização de frutose indicou que a expressão do gene HXT3 (resultado de um alelo mutante na espécie), transportador de hexose em S. cerevisiae, era o responsável pela utilização de frutose similar ao tido nas cepas comerciais (GUILLAUME et al., 2007).

Pressões seletivas em razão de desequilíbrios estruturais na composição da uva, gerando alta acidez em vinhos brancos (BLANCO; VÁZQUEZ-ÁLEN; LOSADA, 2008), ou, superamadurecimento da fruta, com teor de açúcar acima do padrão (MIKI et al., 2008), mostram que é possível isolar entre as espécies da fermentação espontânea, leveduras S. cerevisiae que se destacam pela sobrevivência nessas condições e com boa produção de etanol. Contudo, do exame em 787 cepas de S. cerevisiae, isoladas de muitos substratos de diversas partes do mundo, foi possível correlacionar a taxa de fermentação, produção de etanol e acidez volátil melhores com as culturas iniciadoras encontradas em vinhos e vinharias, em detrimento daquelas isoladas do mosto e da uva (CORTE et al., 2006).

Além disso, nas fermentações espontâneas o crescimento populacional não é estável e pode levar dias até que a biomassa atinja um número satisfatório para degradar o açúcar por completo e produzir álcool. Em fermentados de gabiroba Campomanesia pubescens, o inóculo de S. cerevisiae UFLA CA 1162 produziu já nos primeiros dias populações estáveis de $9 \log$ céls/mL, em comparação com leveduras de fermentação espontânea, as quais tiveram um crescimento de 3.7 a $8.1 \log$ céls/mL após 14 dias (DUARTE et al., 2009). Além disso, a diversidade de espécies da fermentação espontânea pode ser muito alterada sob a influência de sedimento-mãe. O teste com cepas inoculadas e selvagens em barris de vinho Vinsanto, mostrou que na presença do sedimento-mãe (composto de ácidos graxos, esteróis e outros nutrientes), a biodiversidade de $S$. cerevisiae selvagens é grande, porem nas leveduras inoculadas, o sedimento não afeta o inóculo e ainda provê compostos para aumentar seu crescimento populacional (DOMIZIO; MANAZZU; CIANI, 2009).

Apesar das muitas desvantagens de se conduzir fermentações espontâneas em escala comercial, uma das vantagens está na seleção e teste de novas espécies e cepas como culturas iniciadoras puras ou como culturas iniciadoras mistas, a partir das fermentações espontâneas para as análises laboratoriais. Muitas espécies puderam ser isoladas e identificadas com a prática das fermentações espontâneas: é o que mostra a pesquisa realizada com sementes de umbu Spondias tuberosa, na qual se chegou à espécie do ascomiceto Candida floricula R-107 como a cepa capaz de produzir "vinho de umbu” com padrão estatisticamente superior ao de outras espécies (MELO et al., 2007). Um teste realizado no mosto de uvas brancas Pinot Grigio, Roditis e Debina, submetidos a diferentes temperaturas $\left(12\right.$ e $\left.20^{\circ} \mathrm{C}\right)$ permitiu selecionar cepas $S$. cerevisiae como culturas puras na elaboração de vinhos semisecos, além de indicar a espécie de levedura Kloeckera apiculata para futuros testes com potencial em culturas mistas (PAPATHANASIOU et al., 2006).

Em um outro estudo, ainda, espécies de leveduras não Saccharomyces foram avaliadas com base na formação de éster, selecionando-se os melhores gêneros Pichia e Hanseniaspora, da qual Hanseniaspora osmophila 1471 destacou-se pelo seu potencial de formação de 2-feniletil acetato e alta Evidência, Joaçaba v. 8 n. 1-2, p. 57-84, janeiro/dezembro 2008 
taxa de fermentação de açúcares do mosto. Além disso, H. osmophila teve produção de ácido acético, cadeia de ácidos graxos e etil acetato (compostos indesejáveis) dentro dos padrões de aceitabilidade para vinhos, sugerindo-se seu teste em culturas mistas com S. cerevisiae (VIANA et al., 2008).

Pesquisas de cunho protocolar são importantes para a seleção de cepas em ensaios de fermentação e desenvolvimento como culturas iniciadoras. De acordo com critérios fisiológicos, tecnológicos e ecológicos, o isolamento da levedura S. cerevisiae MMf9 com fenótipo killer, em vinhos tintos do Norte da Patagônia, foram desenvolvidos em dois passos: seleção com base nas propriedades tecnológicas e qualitativas, entre as cepas selvagens do ensaio e interação com cepas killer selvagens e comerciais (LOPES et al., 2007b). Em seguida, avaliou-se a implantação dessa mesma cepa na elaboração de vinho em adegas tradicionais e modernas, na qual, S. cerevisiae MMf9 se desenvolveu melhor na adega moderna (80\% contra apenas $40 \%$ da adega tradicional) e mais ainda que as cepas comerciais comumente utilizadas para este vinho tradicional argentino (LOPES et al., 2007a). Há, ainda, na literatura atual, uma técnica de isolamento de cepas de leveduras não-recombinantes por meio de evolução adaptativa, na qual um sistema de fermentação aglomerada seqüencial é provido ao vinho, de forma que, passadas algumas centenas de gerações do microrganismo, mutantes haploides podem ser isolados e avaliados quanto ao seu metabolismo, sobretudo, para catabolizar açúcares (MCBRYDE et al., 2006).

Com base na continuidade do processo fermentativo, algumas pesquisas centram esforços para desvendar as relações entre os efeitos das variáveis físico-químicas e a biologia molecular e fisiologia de culturas iniciadoras na obtenção dos resultados desejados para o seu vinho. Pizarro et al. (2008) compararam o crescimento de cepas $S$. cerevisiae laboratorial e industrial sob duas condições de temperatura $\left(15\right.$ e $\left.30^{\circ} \mathrm{C}\right)$, com nitrogênio limitado, anaerobiose e culturas quimioestáticas constantes, para avaliar a fisiologia e as respostas transcripcionais de ambas. Identificaram que à $30{ }^{\circ} \mathrm{C}$ havia mais mobilização de resposta a esses estresses nessas cepas e que, sob estresse, S. cerevisiae industrial mobiliza recursos para produção de biomassa, enquanto que, S. cerevisiae laboratorial, para agir na fermentação.

O monitoramento de genes relacionados à resposta ao estresse, seja osmótico, oxidativo, térmico ou nutricional, auxiliam no entendimento das relações dessas variáveis com o crescimento e performance fermentativa das culturas iniciadoras. Utilizando-se um gene marcador HSP12, foi possível detectar as mudanças nos níveis de RNAm de dois dos genes relacionados a estresse em S. cerevisiae, GPD1 e TRX2, sugerindo que os estresses osmótico e oxidativo afetam a produção da biomassa das leveduras (PÉREZ-TORRADO; BRUNO-BÁRCENA; MATALLANA, 2005). Os genes requeridos para expressar tolerância máxima a etanol em cepas S. cerevisiae (TEIXEIRA et al., 2009), tolerância a pouco ou nenhum nitrogênio como nutriente no meio (MENDES-FERREIRA et al., 2007a) e respostas transcripcionais a esse estresse (MENDES-FERREIRA et al., 2007b), bem como genes requeridos para expressar ADH2 (isoenzima álcool desidrogenase) em leveduras Saccharomyces bayanus V5 de vinhos 
cereja envelhecidos (MAESTRE et al., 2008), são considerados importantes para o entendimento e garantia de um processo fermentativo contínuo.

Atualmente, o uso de leveduras como culturas iniciadoras para exercer uma ótima fermentação alcoólica e assegurar a reprodutibilidade da elaboração do vinho mantendo a qualidade padrão, está evoluindo no mesmo ritmo da biotecnologia. Os melhoramentos genéticos de cepas específicas para processos em determinados tipos de vinhos, os quais geram características organolépticas pontuais desejáveis, são provas do refinamento dos conhecimentos a respeito das leveduras em vinhos. Alguns desses melhoramentos genéticos podem trazer vantagens em etapas específicas do processo de vinificação, a exemplo da clarificação e filtração das leveduras S. cerevisiae modificadas geneticamente com atividade pectinolítica, promovendo aumento na intensidade da cor de vinhos tintos (FERNANDEZ-GONZALEZ et al., 2005). Na etapa de clarificação e recobrimento do vinho, o acesso a estratégias moleculares para otimizar o comportamento floculante de S. cerevisiae FY23, sob o controle transcripcional dos genes ADH2 e HSP30, permite a essas células características a respeito de sua parede celular (hidrofobicidade, formação de biofilme e propriedades de adesão ao substrato) que passam a satisfazer os requerimentos desta etapa (GOVENDER et al., 2008).

As culturas iniciadoras comerciais, em geral, não satisfazem todas as etapas da vinificação, entretanto, muitas outras modificações genéticas e da expressão gênica são conduzidas de modo a evoluir a enologia a té mesmo nos ricos detalhes. Por exemplo, vinhos brancos submetidos a altas temperaturas ou estocados por longo período tendem a formar uma fina espuma, de aparência potencialmente estranha ao consumidor. Pensando nisso, González-Ramos, Cebollero e Gonzalez (2008) desenvolveram, com base em testes de deleção de alelos KNR4 em cepas $S$. cerevisiae recombinantes, leveduras capazes de lançar proteínas chaperonas para proteger o produto dessas proteínas agregadas que formam a espuma sem perder, contudo, seu potencial tecnológico de fermentação. Um outro estudo de melhoramento genético em leveduras, atém-se a prevenir os riscos da dispersão na natureza do descarte de leveduras transgênicas de vinhos, que depois possam vir a se combinar geneticamente com as leveduras naturais. Para isso, desenvolveram uma cepa estéril S. cerevisiae ime1- $\Delta$, incapaz de esporular ou somar-se a outras cepas de leveduras (RAMÍREZ; AMBRONA, 2008).

$\mathrm{Na}$ continuidade dos estudos de microbiologia aplicada com S. cerevisiae, vinhos brancos espumantes se beneficiam da autofagia da levedura ao final da fermentação alcoólica, quando da carência de nutrientes (nitrogênio ou carbono) no meio, da depleção da proteína Ald6 (acetaldeído desidrogenase), ou ainda, da deleção da porção final 3' da Open Reading Frame (ORF) de uma cópia simples de BCY1 semidominante do genoma de S. cerevisiae, capaz de induzir a esta ação (CEBOLLERO; GONZALEZ, 2006, TABERA; MUÑOZ; GONZALEZ, 2006). Ainda a respeito dos vinhos brancos espumantes, dados obtidos de um estudo mostram como as leveduras afetam quantitativamente a composição final química e volátil nas garrafas seladas e o quanto isso repercute no perfil sensorial, de modo independente da variedade do mosto ou da safra anual (TORRENS et al., 2008).

Evidência, Joaçaba v. 8 n. 1-2, p. 57-84, janeiro/dezembro 2008 
A otimização das culturas iniciadoras de fermentação alcoólica, a partir da requisição do mercado de bebidas fermentadas por vinhos com mais baixo teor alcoólico, culminou com o desenvolvimento da cepa geneticamente modificada S. cerevisiae GPD1 Ald6. Esta codifica para as enzimas glicerol3P-desidrogenase e para a deleção de acetaldeído desidrogenase, que, em outras palavras, significa uma levedura capaz de converter eficientemente o açúcar em glicerol sem formar acetato. Porém, em testes realizados com três cepas comerciais, houve produção final de acetoína e 2,3-butenodiol, os quais geraram odor ruim ao vinho (CAMBON et al., 2006). Novas modificações nessa levedura corrigiram o problema através da supraexpressão de BDH1 (enzima responsável pela redução de acetoína e 2,3-butenodiol a 2,3-butanodiol), neutralizando odores ruins do vinho e permitindo a redução do etanol em até 3 graus alcoólicos (EHSANI et al., 2009).

\subsection{FERMENTAÇÃO MALOLÁCTICA}

A fermentação maloláctica é caracterizada pela deacidificação do meio pela ação de bactérias ácidolácticas responsáveis pela transformação do ácido L-málico em L-láctico e $\mathrm{CO}_{2}$. Nesse processo, há dois aspectos básicos considerados para a seleção de culturas iniciadoras de fermentação maloláctica em vinhos: a compatibilidade das culturas com o ambiente pós-fermentação alcoólica; a contribuição desejável das diferentes cepas de bactérias malolácticas, sobre o produto final. Para uma boa indução das fermentações malolácticas é crítico que haja preparação adequada de bactérias ácido lácticas capazes de sobreviver nas condições vínicas deixadas pelas leveduras (KÖNIG; UNDEN; FRÖHLICH, 2009). Entre essas condições, adversas às bactérias, estão os ácidos fenólicos, o pH ácido, o alto conteúdo de etanol, a presença de $\mathrm{SO}_{2}$ e a depleção de/a falta de mecanismos para acesso aos nutrientes.

O sucesso biológico da deacidificação de compostos do vinho hoje, têm sido atribuído à bactéria maloláctica Oenococcus oeni, a qual apresenta as melhores características reunidas em termos de resistência a estresses e capacidade de conversão de ácido málico em ácido láctico, além da formação de outros compostos requeridos para muitos tipos de vinhos. Em um estudo recente, com cepas O. oeni VP41 (Lallemand Inc, Montreal, Canada), a fermentação maloláctica conduzida em vinhos Amarone $(\sim 17 \%(v / v)$ de etanol) da África do Sul, ocorreu em razão de uma estratégia prévia de aclimatação da bactéria em solução água-vinho (1:1), por 24 e 48 respectivamente, inoculadas com as leveduras da fermentação alcoólica, resultando na conversão completa do ácido málico (ZAPPAROLI et al., 2009).

Para se obter culturas iniciadoras $O$. oeni prontas para uso, outras estratégias são elaboradas pelos cientistas com potencial de ativar mecanismos específicos de resposta a estresses contidos no seu genoma. Os autores Zhao et al. (2009) sugerem a seleção destas bactérias em tratamento sob estresse ácido, no qual mecanismos de resposta observados acusam a formação de ácidos lactobacílicos concentrados ao redor da membrana lipídica que fornecem a resistência necessária ao $\mathrm{pH}$ do vinho. 
Um outro estudo realizado, com indução de resposta bacteriana a quantidades de $\mathrm{SO}_{2}$, no sentido de determinar em termos quantitativos a contribuição do estado fisiológico para a fermentação maloláctica, gerando subpopulações de células viáveis, mas não cultiváveis, permitiu otimizar os bioprocessos e o controle da fermentação maloláctica em escala industrial (QUIRÓS et al., 2009).

O efeito de ácidos fenólicos, compostos resultantes da fermentação alcoólica, são estudados nas bactérias ácido lácticas. Estas moléculas se apresentam na forma de ácidos hidroxicinâmicos (ácidos p-cumárico, caféico e ferúlico) e hidroxibenzoicos (ácidos p-hidroxibenzoico, protocatecoico, gálico, vanílico e siríngico). Em uma investigação a respeito da integridade da membrana plasmática de $O$. oeni e Lactobacillus hilgardii aos ácidos fenólicos, o ácido p-cumárico causou o mais forte impacto, contribuindo para a redução da viabilidade destas células (CAMPOS et al., 2009a). Na sequencia desse estudo, procurou-se avaliar o efeito dos ácidos fenólicos sobre o metabolismo da glicose e ácido cítrico das mesmas cepas, obtendo-se que, apesar do decaimento do metabolismo em ambas, O. oeni, ainda que não aumentasse sua biomassa, foi o único microrganismo capaz de realizar a fermentação maloláctica (CAMPOS et al., 2009b).

$\mathrm{Na}$ base molecular das respostas a estresses por etanol e pH ácido nas bactérias do vinho, Olguín, Bordons e Reguant (2009) analisaram a resposta transcripcional da expressão gênica da via citrato em O. oeni PSU-1, a qual dependendo do gene envolvido resulta na formação de ácido acético ou diacetil como produto final da reação. Em relação ao $\mathrm{SO}_{2}$, microvinificações simuladas em mosto de uvas vermelhas com três cepas de $O$. oeni inoculadas individualmente e como cultura mista, testadas para responder $\mathrm{a} \mathrm{SO}_{2}$, ácido dodecanoico e cobre, apresentaram decaimento na fermentação maloláctica e no crescimento, sendo o melhor resultado com as cepas comercial e isolada da adega e os piores resultados obtidos com as cepas em cultura mista e sob influência de ácido dodecanoico (CARRETÉ et al., 2006).

Um acréscimo da literatura atual com relação ao $\mathrm{SO}_{2}$ - composto preservativo - em vinhos brancos, aufere que sua junção com o acetaldeído formado durante a fermentação alcoólica, afeta negativamente o metabolismo de conversão do ácido málico pelas cepas $O$. oeni, causando pausas na fermentação (OSBORNE; MORNEAU; ORDUÑA, 2006). A possibilidade de redução deste preservativo, importante para conter a proliferação de microrganismos contaminantes no vinho, é avaliada também pela sua substituição com o uso de bacteriocinas, como a plantaricina, produzida por Lactobacillus plantarum, e a nisina em concentrações subinibitórias adicionadas ao vinho com redução de $\mathrm{SO}_{2}$ (ROJO-BEZARES et al., 2007a,b).

Algumas bactérias no vinho se tornam contaminantes pelo fato de produzirem precursores carcinogênicos, como as aminas biogênicas e o etil carbamato. O efeito interativo de algumas variáveis, como $\mathrm{pH}$, etanol, piridoxal-5-fosfato, arabinose e $\mathrm{SO}_{2}$ sobre a produção de aminas biogênicas pelas cepas O. oeni T56 revelou que nas condições finais da fermentação maloláctica, maior pH e menor conteúdo de etanol e piridoxal-5-fosfato, a atividade de descarboxilases das bactérias é aumentada, contribuindo Evidência, Joaçaba v. 8 n. 1-2, p. 57-84, janeiro/dezembro 2008 
para a formação das aminas biogênicas (GARDINI et al., 2005). Outros autores corroboram com a pesquisa e acrescentam quais os tipos de aminas podem aparecer de acordo com a espécie, a quantificação dessa produção e, ainda, que nas cepas comerciais a formação de aminas biogênicas é bem menor que nas cepas selvagens (LANDETE; FERRER; PARDO, 2007, HERNÁNDEZ-ORTE et al., 2008, MARQUES; LEITÃO; ROMÃO, 2008, NANNELLI et al., 2008, MANFROI et al., 2009). $\mathrm{Na}$ investigação biomolecular do gene odc (ornitina descarboxilase), em O. oeni RM83, formador da amina biogênica putrescina, indícios apontam a origem do lócus de biossíntese desta amina e a transferência horizontal deste gene entre as cepas desta bactéria (MARCOBAL et al., 2006).

Com o etil carbamato e seu precursor citrolina, igualmente às aminas biogênicas, as condições finais da fermentação maloláctica contribuem para o seu surgimento. Em meio simulado com testes em cepas de O. oeni e L. plantarum, observou-se que, se a conversão do ácido málico não for eficiente, e sob níveis de $\mathrm{pH}$ mais alto, apenas O. oeni passa a degradar a arginina, e consequentemente, formar a citrulina, aumentando o potencial de etil carbamato no meio (ROMERO et al., 2009). Em outros testes com cepas comerciais de O. oeni, após três semanas da fermentação maloláctica houve a produção aumentada da citrulina, o que na presença de sedimento-mãe contendo algumas leveduras foi ainda maior. As cepas comerciais, bem como produtos de autólise de leveduras (uria, principalmente) contribuem para a formação de etil carbamato, contudo, é possível prevenir isto com a inoculação de uma cultura iniciadora pura de O. oeni e com a inibição da biomassa bacteriana após a fermentação maloláctica (TERRADE; ORDUÑA, 2006; UTHURRY et al., 2006).

Em relação aos estudos de requerimentos nutricionais das bactérias malolácticas, fontes de carbono, nitrogênio, fosfato, manganês, aminoácidos e vitaminas são nutrientes comuns para Oenococci e Lactobacilli. A partir disso, um meio quimicamente definido foi elaborado composto de 44 constituintes para prover um meio de cultura adequado a testes laboratoriais, com sucesso em 22 cepas dentre Oenococcus, Lactobacillus e Pediococcus, permitindo variações protocolares, a exemplo de uma riboflavina que pode favorecer as cepas de O. oeni (TERRADE; ORDUÑA, 2009; TERRADE et al., 2009). A disponibilização de nutrientes ao vinho por essas bactérias é pesquisada na base da regulação de suas atividades enzimáticas. Segundo Nadra et al. (2005), proteases com ação sobre frações macromoleculares nitrogenosas em vinhos tintos argentinos, na presença de $\mathrm{SO}_{2}$ e etanol, liberam fatores de crescimento, os aminoácidos essenciais para as cepas O. oeni, logo após a fermentação alcoólica.

Em estudos recentes, aprofunda-se a importância das enzimas responsáveis pela formação de compostos que conferem propriedades organolépticas requeridas (ou não) aos vinhos. Por exemplo, a viscosidade, propriedade que interfere na aparência do produto final, é bastante influenciada pela expressão da atividade de glicosiltransferase, do gene gtf em Pediococci, presente também no genoma de O. oeni. Este gene, quando expressado $\left(\mathrm{gtf}^{+}\right)$, torna a bactéria mais resistente aos estresses do meio $(\mathrm{pH}$ e $\mathrm{SO}_{2}$ ), por meio da formação de fatores de adesão para formar biofilme (DOLS-LAFARGUE et al., 
2008). Em um outro estudo, detectou-se o gene dps (da produção de exopolissacarídeos) nas cepas de P. damnosus e O. oeni, os quais aumentam a viscosidade dos vinhos e cidras, sendo não requeridos para o processo. Sua identificação por técnica molecular pode auxiliar na prevenção destes contaminantes (WALLING; GINDREAU; LONVAUD-FUNEL, 2005).

O aroma, outra propriedade organoléptica importante do vinho, é lançado pelas bactérias malolácticas na forma de terpenos, norisoprenoides, fenóis e vanilinas, cujos precursores glicosídicos são extraídos da uva não floral por esses microrganismos. Em um meio sintético testado, O. oeni, que comprovadamente apresenta capacidade hidrolítica significativa contra subtratos glicosídicos, foi a única bactéria capaz de completar essa atividade em 45 dias de fermentação, comparado a $L$. brevis e L. casei (GRIMALDI; BARTOWSKY; JIRANEK, 2005, HERNÁNDEZ-ORTE et al., 2009). Um outro estudo mais específico, envolvendo bactérias do vinho e fenóis, avalia a influência da inoculação das culturas iniciadoras de fermentação maloláctica, em laboratório e em adega, impedindo

o desenvolvimento de leveduras Brettanomyces, que são consideradas contaminantes por alterar a composição do vinho, produzindo fenóis voláteis (GERBAUX et al., 2009).

O potencial de biodeacidificação do vinho é também estudado com leveduras transgênicas para realizar a fermentação maloláctica. A cepa S. cerevisiae ML01 foi concebida com o gene transportador de malato (mae1) de Schizosaccharomyces pombe e o gene maloláctico (mleA) de O. oeni integrados ao genoma de S. cerevisiae no lócus URA3. Em vinhos Chardonnay, já durante a fermentação alcoólica, foi capaz de descarboxilar malato a lactato sem afetar a biomassa e a produção de etanol (HUSNIK et al., 2007). Testes em vinhos Vignole, comparado a duas leveduras selecionadas e uma bactéria maloláctica inoculada, S. cerevisiae ML01 conseguiu converter 100\% do ácido málico em ácido láctico em cerca de 60 horas de fermentação e com os maiores níveis de $\mathrm{SO}_{2}$ presentes no meio. A utilidade desta cepa é bastante promissora na indústria de vinhos, porem os autores alertam para maiores estudos em relação ao o controle da quantidade de ácido láctico, dependendo do estilo de vinho desejado (MAIN; THRELFALL; MORRIS, 2007).

\subsection{CULTURAS MISTAS}

As culturas iniciadoras comerciais são geralmente compostas de mais de um microrganismo, visando a somar suas ações para se obter o efeito desejado no produto final. Os microrganismos utilizados como culturas iniciadoras mistas em vinhos (mixed cultures) são estudados com as leveduras, para a fermentação alcoólica, ou na base da interação levedura-bactéria. Para se avaliar melhor a ecologia de colonização complexa do meio de fermentação, dois aspectos devem ser considerados: os resultados positivos das culturas mistas sobre o produto a ser fermentado e os resultados negativos e seus efeitos antagonísticos.

No primeiro caso, as culturas iniciadoras adicionadas agem sobre o substrato, resultando em benefícios ao produto. Por exemplo, a inoculação sequencial de Pichia fermentans como inóculo de

Evidência, Joaçaba v. 8 n. 1-2, p. 57-84, janeiro/dezembro 2008 
Culturas iniciadoras de fermentação em vinhos

S. cerevisiae no mosto, faz aumentar quantitativa e qualitativamente uma gama de compostos que em longo prazo, proporcionam mais sabor ao vinho (CLEMENTE-JIMENEZ et al., 2005). Do mesmo modo, estudos de seleção e testes com culturas mistas chegaram a algumas das melhores espécies de leveduras apiculadas capazes de interagir positivamente com S. cerevisiae, resistir a fatores de estresse do meio e gerar propriedades organolépticas desejáveis ao vinho, são elas: Hanseniaspora guilliermondii (MOREIRA et al., 2005, 2008), Hanseniaspora osmophila (VIANA et al., 2009) e Kloeckera apiculata (MENDOZA et al., 2009).

No caso particular em que a fermentação alcoólica é precedida por uma etapa, como nos vinhos de arroz, nos quais bolores e leveduras devem possuir interação estável entre si para agilizar o processo da degradação do amido e fazer a fermentação dos açúcares, Amylomyces rouxii, Amylomyces rouxii var. rouxii, Rhizopus oligosporus e Rhizopus oryzae são as cepas principais testadas para interagir bem com $S$. cerevisiae. Além dessa compatibilidade que apresentam, das melhores atividades de amiloglicosidases e da produção de etanol, também é estudada a adição de duas ervas locais do Vietnã (Foeniculum vulgare Miller e Syzygium aromaticum L.) usadas como nutrientes suplementares para aumento da biomassa microbiana. O resultado tem sido um vinho de arroz com sabor superior ao vinho de arroz comercializado sem o uso da técnica (DUNG; ROMBOUTS; NOUT, 2005, 2006).

Nos efeitos negativos, a inoculação de culturas iniciadoras no meio de vinificação deve prover a continuidade do processo, isto é, não pode haver paradas ou lentidão ao longo do processo fermentativo. Fermentações ensaiadas com múltiplos iniciadores, como por, exemplo, Hanseniaspora uvarum, Torulaspora delbrueckii e Kluyveromyces thermotolerans, somados à S. cerevisiae, renderam resultados negativos ao processo, observando-se, além de uma baixa cinética de fermentação, a grande produção de compostos orgânicos indesejáveis ao vinho, como o etil acetato (CIANI; BECO; COMITINI, 2006). O mesmo ocorreu na pesquisa com o híbrido S.cerevisiae-S. uvarum junto com S. cerevisiae: as culturas mistas produziram grandes quantidades de acetaldeído, os híbridos não resistiram a fatores de estresse e a cinética de fermentação ficou prejudicada (CHERAITI; GUEZENEC; SALMON, 2005). Aliás, as causas de mortes de culturas mistas, de acordo com Pérez-Nevado et al. (2006) ainda permanecem mal esclarecidas na literatura. Estudando a morte precoce de culturas de H. guilliermondii e H. uvarum inoculadas com S. cerevisiae, os autores observaram que, entre testes nas monoculturas e nas culturas mistas, o alto conteúdo de etanol e as toxinas killer não geravam qualquer efeito negativo sobre os cultivos puros. Sugeriram, dessa forma, a necessidade de se avaliar a antibiose da cepa $S$. cerevisiae com as cepas não Saccharomyces.

Relações antagonísticas são mais comuns entre fungos e bactérias, resultantes da atividade competitiva quando a inoculação dessas duas culturas é imprópria ou mal compreendida. Os mecanismos que governam essa interação já foram revisados por Alexandre et al. (2004) e aqui serão citados apenas os trabalhos atuais, não incluídos naquele. $\mathrm{O}$ efeito da inibição de leveduras $S$. cerevisiae nas bactérias O. oeni em relação à competição por nutrientes e antibiose, foram obtidos em meio de 
cultura e comparados a amostras de fermentação industrial (ARNINK; KLING-HENICK, 2005). Como resultados, além de não haver crescimento das bactérias em $88 \%$ das placas, a fermentação maloláctica não ocorreu adequadamente no vinho. Em contrapartida, Jussier, Morneau e Orduña (2006) investigaram o efeito da inoculação simultânea da levedura e da bactéria em vinhos Chardonnay de clima frio e obtiveram êxito quanto à cinética de fermentação e outros parâmetros-chave da elaboração de vinhos brancos supersecos na utilização de ambos os microrganismos.

Porem nem todas as cepas reagem de forma regular, apenas inibindo ou apenas estimulando. Nehme, Mathieu e Taillandier (2008) discutiram a existência de vários graus de inibição e estimulação, dependendo das cepas de levedura e bactéria selecionadas. Nesta pesquisa, uma mesma levedura foi capaz de inibir e estimular diferentes cepas da bactéria maloláctica O. oeni e, mesmo sob inibição, havia um grau de variação do efeito inibitório observado. Outros estudos que abordarão análises a respeito de mecanismos relacionados ao efeito inibitório da levedura sobre a bactéria dos vinhos, compõem as revisões sobre: dinâmica de populações de cepas O. oeni sob efeito de $\mathrm{SO}_{2}$ e cepas de levedura (REGUANT et al., 2005); efeito da atividade proteolítica das leveduras sobre O. oeni e a fermentação maloláctica (GUILLOUX-BENATIER et al., 2006); atividade inibitória de leveduras iniciadoras de fermentação sobre as bactérias malolácticas, com conversão parcial de ácido málico (COMITINI; CIANI, 2007); e inibição da fermentação maloláctica por peptídeo produzido por S. cerevisiae durante a fermentação alcoólica (OSBORNE; EDWARDS, 2007).

\section{MÉTODOS DE ESTUDO EM CULTURAS INICIADORAS - A BIOTECNOLOGIA EM DESTAQUE}

Uma das alternativas mais simples para se estudar culturas iniciadoras de fermentação em vinhos compreende inoculá-las em meio de vinificação e fazer as análises de parâmetros enológicos gerados no processo, tal como exposto na pesquisa de Dorneles et al. (2005), a qual avalia a inoculação de leveduras selecionadas e não selecionadas a respeito da padronização de vinhos, conforme a legislação brasileira.

Contudo, para se realizar ensaios com culturas fermentadoras, cujas variáveis possam ser isoladas e analisadas a fundo, o meio sintético simulado, referido como ensaio de microvinificação, tem sido freqüentemente utilizado por muitos pesquisadores (CARRETÉ et al., 2006; FERNANDEZGONZALEZ et al., 2005 LOPES et al., 2007; VIANA et al., 2008; ZAPPAROLI et al., 2009).

Além dessas técnicas, a grande contribuição para aprofundamentos com o uso de culturas iniciadoras concentra-se atualmente na biotecnologia, por meio de estudos genéticos e moleculares. Desde a descrição do genoma de O. oeni PSU-1, em 2005, outros estudos na área evoluíram rapidamente alguns conhecimentos acerca das culturas iniciadoras de fermentação maloláctica. A caracterização da

Evidência, Joaçaba v. 8 n. 1-2, p. 57-84, janeiro/dezembro 2008 
Culturas iniciadoras de fermentação em vinhos

plasticidade de seu genoma, por exemplo, sugeriu a estratégia de O. oeni em adquirir genes de outras bactérias como forma de aumentar seu desempenho no vinho (BON et al., 2009). Uma esterase intracelular, envolvida na catálise de hidrólise e síntese de ésteres, foi clonada do genoma de O. oeni PSU-1 e caracterizada com os seus parâmetros ótimos de funcionamento em vinhos (SUMBY et al., 2009).

Os métodos moleculares de tipagem genética apresentam uma variedade de aplicações para estudos com esses microrganismos. A tipagem de sequência multilocus, por exemplo, informou as subpopulações de O. oeni formadas por recombinações intergênicas, aclarando como a disseminação de alelos entre as cepas evoluiu (BILHÉRE et al., 2009); entretanto, a técnica perde precisão em termos da discriminação de cepas de leveduras do vinho, tendo melhores resultados com o uso de outra técnica: RFLP mitocondrial (MUÑOZ et al., 2009).

O uso de marcadores baseados em PCR são extremamente utilizados na identificação e monitoramento de espécies do vinho, apresentando algumas variações da técnica como:

a) Análise de restrição parcial de 26S DNAr a respeito da dinâmica de populações de leveduras não Saccharomyces em vinhos tintos (COUTO; REIZINHO; DUARTE, 2005) ou enzimas de restrição a partir de produtos de PCR com gene 5.8S RNAr para identificar cepas de S. cerevisiae na IDY do Hamei (um preparado sólido usado no vinho de arroz hindu) (JEYARAM et al., 2008);

b) Real time-PCR para identificar e quantificar em tempo real as culturas fermentadoras S. cerevisiae e suas UFCs mínimas a serem inoculadas em vinhos doces (3.8 UFC) e tintos (5 UFC) sem préenriquecimento do mosto (MARTORELL; QUEROL; FERNÁNDEZ-ESPINAR, 2005), ou enumerar o total de bactérias ácido lácticas e prevenir as não Oenococci contaminantes (NEELEY; PHISTER; MILLS, 2005);

c) PCR-TGGE com uso de novos primers anelando em regiões ITS2 para distinguir de modo rápido e no próprio mosto entre espécies de $S$. cerevisiae e $S$. paradoxus (MANZANO et al., 2005), bem como detectar bactérias contaminantes, p.ex. P. parvulus, usando como marcador o gene da região rpoB em PCR-DGGE (RENOUF et al., 2006).

A citometria de fluxo e o uso de anticorpos fluorescentes em marcadores da célula, permitiu avaliar a viabilidade das cepas e mudanças nas populações de fermentadores do vinho em tempo real (RODRIGUEZ; THORNTON, 2008). Em outro estudo, a citometria de fluxo auxiliou na determinação da vitalidade das leveduras por medição de seu pH intracelular nas fases exponencial e estacionária, a partir da qual providenciou um protocolo rápido e rotineiro para detecção de subpopulações de leveduras existentes no mosto (WEIGERT et al., 2009). 
Estudos para se avaliar a expressão gênica com uso de Heat Shock Protein (HSP) seguidos por outras técnicas (immunoblotting e PCR) têm sido usadas na seleção mais rápida de cepas de $O$. oeni para fins de fermentação (COUCHENEY et al., 2005) e, também, no entendimento da base molecular de adaptação de S. cerevisiae, comparando-se suas transcriptômica e proteômica para enzimas requeridas no metabolismo do enxofre (ZUZUARREGUI et al., 2006). Em outro trabalho, a comparação transcriptômica foi realizada entre cepas de leveduras industriais para diferenciação fenotípica, e verificou-se que tais diferenças nas propriedades da parede celular, respostas a estresse e produção metabólica durante a fermentação alcoólica, compunham uma rede molecular complexa, cuja regulação era estritamente específica a cada cepa amostrada (ROSSOUW et al., 2009).

A regulação da expressão gênica do operon de síntese macromolecular em O. oeni foi comparada ao de outras bactérias Gram-positivas, aproximando-a filogeneticamente a Lactococcus lactis, o que auxilia a preparação de culturas iniciadoras de melhor potencial para o vinho (ARVIK et al., 2005). Em um outro estudo, para determinar a genética de lançamento de tióis voláteis por $S$. cerevisiae na fermentação alcoólica, os cientistas fizeram uso da espectometria de massa, a qual identificou os compostos de aroma expressados em testes com deleção de genes ligados ao metabolismo de liases carbono-sulfurosas nas leveduras (HOWELL et al., 2005).

Por último, um protocolo de eletroporação testado em O. oeni usando etanol como agente fluidizante da membrana otimizou o processo de inserção de DNA transformante na bactéria. O vetor pGID052 foi capaz de transformar a cepa O. oeni ATCC BAA-1163 que, em seguida, passou a expressar uma proteína ClpL2 avaliada (ASSAD-GARCIA et al., 2008).

\section{PERSPECTIVAS DE ESTUDOS}

O emprego das culturas iniciadoras de fermentação é cada vez mais comum na indústria, ao passo que estudos detalhados no campo científico avançam. Muitos trabalhos recentes demonstram os efeitos da biotecnologia no sentido de otimizar e potencializar o uso de culturas iniciadoras, sobretudo, em fermentações com culturas mistas. A ecologia e a colonização complexa do meio de fermentação têm sido uma tendência nos últimos anos.

Além disso, as técnicas moleculares contribuem com o entendimento dos processos de resposta a estresses na base molecular, permitindo que alterações pontuais e correções possam ser realizadas. Outra tendência é intensificar os estudos com culturas iniciadoras, utilizando-se de métodos de tipagem molecular, especialmente as técnicas baseadas em PCR. Tudo isso contribui, enfim, para o sucesso no processo de elaboração de vinhos. 
Nota explicativa

${ }^{1}$ I- As bases de busca e obtenção dos artigos na íntegra compõem-se dos seguintes portais (e instituição):1) Science Direct; 2) Scopus; 3) Ebsco Host Database; 4) Sistema COMUT, via Unoesc - Campus de Videira.

\section{REFERÊNCIAS}

ALEXANDRE, H. et al. Saccharomyces cerevisiae - Oenococcus oeni interactions in wine: current knowledge and perspectives. Int J Food Microbiol, v.93, p.141-154. 2004.

AMARANTE, J. O. A. Os segredos do vinho: para iniciantes e iniciados. 2.ed. Mescla Editorial 2005. 568 p.

ARNINK, K; KLING-HENICK, T. Influence of Saccharomyces cerevisiae and Oenococcus oeni Strains on Successful Malolactic Conversion in Wine. Am J Enol Vitic, v. 56, p. 228-237, set. 2005.

ARVIK, T. et al. Identification of the Macromolecular Synthesis Operon of Oenococcus oeni. Am J Enol Vitic, v. 56, p. 60-67, mar. 2005.

ASSAD-GARCÍA, J. S. et al. An improved protocol for electroporation of Oenococcus oeni ATCC BAA-1163 using ethanol as immediate membrane fluidizing agent. Lett Appl Microbiol, v. 47, p. 333-338, 2008.

BILHÈRE, E. et al. Multilocus Sequence Typing of Oenococcus oeni: Detection of Two Subpopulations Shaped by Intergenic Recombination. Appl Environ Microbiol, v. 75, n. 5, p. 1291 1300, mar. 2009.

BLANCO, P.; VÁZQUEZ-ALÉN, M.; LOSADA, A. Influence of yeast population on characteristics of the wine obtained in spontaneous and inoculated fermentations of must from Vitis vinifera Lado. J Ind Microbiol Biotechnol, v. 35, n. 3, p. 183-188, 2008.

BON, E. et al. Oenococcus oeni Genome Plasticity Is Associated with Fitness. Appl Environ Microbiol, v. 75, n. 7, p. 2079-2090, apr. 2009.

CAMBON, B. et al. Effects of GPD1 Overexpression in Saccharomyces cerevisiae Commercial Wine Yeast Strains Lacking ALD6 Genes. Appl Environ Microbiol, v. 72, n. 7, p. 4688-4794, 2006. 
Débora dos Santos, Jane Mary Lafayette Neves Gelinski

CAMPOS, F.M. et al. Cell membrane damage induced by phenolic acids on wine lactic acid bacteria. Int J Food Microbiol, v. 135, p. 144-151, 2009a.

Effect of phenolic acids on glucose and organic acid metabolism by lactic acid bacteria from wine. Food Microbiol, v. 26, n. 4, p. 409-414, jun. 2009b.

CARRETÉ, R. et al. Analysis of Oenococcus oeni Strains in Simulated Microvinifications with Some Stress Compounds. Am J Enol Vitic, v. 57, p. 356-362, set. 2006.

CEBOLLERO, E; GONZALEZ, R. Induction of Autophagy by Second-Fermentation Yeasts during Elaboration of Sparkling Wines. Appl Environ Microbiol, v. 72, n. 6, p. 4121, 4127, 2006.

CHERAITI, N.; GUEZENEC, S.; SALMON, J-M. Redox Interactions between Saccharomyces cerevisiae and Saccharomyces uvarum in Mixed Culture under Enological Conditions. Appl Environ Microbiol v. 71, n. 1, p. 255 260, jan. 2005.

CIANI, M., BECO, L.; COMITINI, F. Fermentation behaviour and metabolic interactions of multistarter wine yeast fermentations. Int J Food Microbiol, v. 108, p. 239-245, apr. 2006.

CLEMENTE-JIMENEZ, J. M. et al. Influence of sequential yeast mixtures on wine fermentation. Int J Food Microbiol, v. 98, p. 301-308, feb. 2005.

COMITINI, F. e CIANI, M. The inhibitory activity of wine yeast starters on malolactic bacteria. Annals of Microbiology, v. 57, n. 1, p. 61-66, 2007.

CORTE, L. et al. Distribution and correlation of three oenological traits in Saccharomyces cerevisiae. Annals of Microbiology, v. 56, n. 1, p. 19-23, 2006.

COUCHENEY, F. et al. A new approach for selection of Oenococcus oeni strains in order to produce malolactic starters. Int J Food Microbiol, v. 105, p. 463-470, dec. 2005.

COUTO, M. M. B.; REIZINHO, R. G.; DUARTE, F. L. Partial 26S rDNA restriction analysis as a tool to characterise non-Saccharomyces yeasts present during red wine fermentations. Int J Food Microbiol, v. 102, p. 49-56, jun. 2005.

Evidência, Joaçaba v. 8 n. 1-2, p. 57-84, janeiro/dezembro 2008 
Culturas iniciadoras de fermentação em vinhos

DOLS-LAFARGUE, M. et al. Characterization of gtf, a Glucosyltransferase Gene in the Genomes of Pediococcus parvulus and Oenococcus oeni, Two Bacterial Species Commonly Found in Wine. Appl Environ Microbiol, v. 74, n. 13, p. 4079-4090, jul. 2008.

DOMIZIO, P.; MANAZZU, I.; CIANI, M. Impact of mother sediment on yeast growth, biodiversity, and ethanol production during fermentation of Vinsanto wine. Int J Food Microbiol, v. 129 , p. 83-87, 2009.

DORNELES, D. et al. Influence of the use of selected and non-selected yeasts in red wine production. Braz Arch Biol Technol, v. 48, n. 5, p. 747-751, sept. 2005.

DUARTE, W. F. et al. Indigenous and inoculated yeast fermentation of gabiroba (Campomanesia pubescens) pulp for fruit wine production. J Ind Microbiol Biotechnol, v. 36, n. 4, p. 557-569, 2009.

. Development of defined mixed-culture fungal fermentation starter granulate for controlled production of rice wine. Innovat Food Sci Emerg Tech, v. 6, p. 429-441, 2005.

DUNG, N.T.P., ROMBOUTS, F.M. e NOUT, M.J.R. Functionality of selected strains of moulds and yeasts from Vietnamese rice wine starters. Food Microbiol v. 23, n. 4, p. 331-340, jun. 2006.

EHSANI, M. et al. Engineering of 2,3-Butanediol Dehydrogenase To Reduce Acetoin Formation by Glycerol-Overproducing, Low-Alcohol Saccharomyces cerevisiae. Appl Environ Microbiol, v. 75, n. 10, p. 3196-3205, may 2009.

FERNANDEZ-GONZALEZ, M. et al. Engineering of an oenological Saccharomyces cerevisiae strain with pectinolytic activity and its effect on wine. Int J Food Microbiol, v. 102, n. 2, p. 173183, jul. 2005.

GARDINI, F. et al. Factors influencing biogenic amine production by a strain of Oenococcus oeni in a model system. Food Control, v. 16, p. 609-616. 2005.

GERBAUX, V. et al. Influence of Inoculation with Malolactic Bacteria on Volatile Phenols in Wines. Am J Enol Vitic, v. 60, p. 233-235, jun. 2009.

GONZÁLEZ-RAMOS, D., CEBOLLERO, E. e GONZALEZ, R. A Recombinant Saccharomyces cerevisiae Strain Overproducing Mannoproteins Stabilizes Wine against Protein Haze. Appl

Evidência, Joaçaba v. 8 n. 1-2, p. 57-84, janeiro/dezembro 2008 
Environ Microbiol, v. 74, n. 17, p. 5533-5540, sept. 2008.

GOVENDER, P. et al. Controlled Expression of the Dominant Flocculation Genes FLO1, FLO5, and FLO11 in Saccharomyces cerevisiae. Appl Environ Microbiol v. 74, n. 19, p. 6041-6052, oct. 2008.

GRIMALDI, A., BARTOWSKY, E. e JIRANEK, V. A survey of glycosidase activities of commercial wine strains of Oenococcus oeni. Int J Food Microbiol, v. 105, n. 2, p. 233-244, nov. 2005.

GUILLAUME, C. et al. Molecular Basis of Fructose Utilization by the Wine Yeast Saccharomyces cerevisiae: a Mutated HXT3 Allele Enhances Fructose Fermentation. Appl Environ Microbiol, v. 73, n. 8, p. 2432-2439, apr. 2007.

GUILLOUX-BENATIER, M. et al. Effects of yeast proteolytic activity on Oenococcus oeni and malolactic fermentation. FEMS Microbiology Letters v. 263, p. 183-188. 2006.

HERNÁNDEZ-ORTE, P. et al. Aroma development from non-floral grape precursors by wine lactic acid bacteria. Food Res Int v. 42, p. 773-781, 2009.

Biogenic amine determination in wine fermented in oak barrels: Factors affecting formation. Food Res Int v. 41, p. 697 706. 2008.

HOWELL, K. S. et al. Genetic Determinants of Volatile-Thiol Release by Saccharomyces cerevisiae during Wine Fermentation. Appl Environ Microbiol v. 71, n. 9, p. 5420-5426, sept. 2005.

HUSNIK, J. I. et al. Functional Analyses of the Malolactic Wine Yeast ML01. Am J Enol Vitic v. 58, n. 42-52, mar. 2007.

JEYARAM, K. et al. Molecular Identification of yeast species associated with Hamei - A traditional starter used for rice wine production in Manipur, India. Int J Food Microbiol, v. 124, p. 115 125, 2008.

JUSSIER, D.; MORNEAU, A. D. ORDUÑA, R. M. Effect of Simultaneous Inoculation with Yeast and Bacteria on Fermentation Kinetics and Key Wine Parameters of Cool-Climate Chardonnay. Appl Environ Microbiol, v. 72, n. 1, p. 221-227. 2006.

KÖNIG, H., UNDEN, G. e FRÖHLICH, J. Biology of Microorganisms on Grapes, in Must and in Wine. BerlinHeidelberg: Springer-verlang, p.

Evidência, Joaçaba v. 8 n. 1-2, p. 57-84, janeiro/dezembro 2008 
Culturas iniciadoras de fermentação em vinhos

LANDETE, J.; M., FERRER, S.; PARDO, I. Biogenic amine production by lactic acid bacteria, acetic bacteria and yeast isolated from wine. Food Control, v. 18, p. 1569-1574, 2007.

LOPES, C. A. et al. Patagonian wines: implantation of an indigenous strain of Saccharomyces cerevisiae in fermentations conducted in traditional and modern cellars. J Ind Microbiol Biotechnol, v. 34, p. 139-149, 2007a.

. Patagonian wines: the selection of an indigenous yeast starter. J Ind Microbiol

Biotechnol, v. 34, p. 539-546, 2007 b.

MAESTRE, O. et al. Effects of ADH2 Overexpression in Saccharomyces bayanus during Alcoholic Fermentation. Appl Environ Microbiol, v. 74, n. 3, p. 702-707, feb. 2008.

MAIN, G. L.; THRELFALL, R .T.; MORRIS, J. R. Reduction of Malic Acid in Wine Using Natural and Genetically Enhanced Microorganisms. Am J Enol Vitic, v. 58, p. 341-345, set. 2007.

MANFROI, L. et al. Influence of alcoholic and malolactic starter cultures on bioactive amines in Merlot wines. Food Chem, v. 116, p. 208 213. 2009.

MANZANO, M. et al. A PCR-TGGE (Temperature Gradient Gel Electrophoresis) technique to assess differentiation among enological Saccharomyces cerevisiae strains. Int J Food Microbiol, v. 101, p. 333-339, 2005.

MARCOBAL, A. et al. Evidence for Horizontal Gene Transfer as Origin of Putrescine Production in Oenococcus oeni RM83. Appl Environ Microbiol, v. 72, n.12, p. 7954-7958. 2006.

MARQUES, A. P.; LEITÃO, M. C.; ROMÃO, M. V. S. Biogenic amines in wines: Influence of oenological factors. Food Chem, v. 107, p. 853-860, 2008.

MARTORELL, P., QUEROL, A.; FERNÁNDEZ-ESPINAR, M. T. Rapid Identification and Enumeration of Saccharomyces cerevisiae Cells in Wine by Real-Time PCR. Appl Environ Microbiol, v. 71, n. 11, p. 6823-6830, nov. 2005.

MATTHEWS, A. et al. Lactic Acid Bacteria as a Potential Source of Enzymes for Use in Vinification. Appl Environ Microbiol, v. 70, n. 10, p. 5715-5731, oct. 2004. 
MCBRYDE, C. et al. Generation of Novel Wine Yeast Strains by Adaptive Evolution. Am J Enol Vitic, v. 57, p. 423-430, dec. 2006.

MELO, D. L. F. M. et al. Identification of Yeasts Isolated from the Pulp in Nature and the Production of Homemade "Umbu" Wine. Braz Arch Biol Technol v. 50, n. 5, p. 887-892, 2007.

MENDES-FERREIRA, A. et al. Saccharomyces cerevisiae Signature Genes for Predicting Nitrogen Deficiency during Alcoholic Fermentation. Appl Environ Microbiol v. 73, n. 16, p. 5363-5369, aug. 2007a.

. Transcriptional Response of Saccharomyces cerevisiae to Different Nitrogen Concentrations during Alcoholic Fermentation. Appl Environ Microbiol, v. 73, n. 9, p. 30493060, may. 2007b.

MENDOZA, L. M. et al. Influence of wine-related physicochemical factors on the growth and metabolism of non-Saccharomyces and Saccharomyces yeasts in mixed culture. J Ind Microbiol Biotechnol ,v. 36, p. 229-237, 2009.

MIKI, T. et al. Potential of yeasts isolated in botrytized grape juice to be new wine yeasts. Food Sci Technol Res, v. 14, n. 14, p. 345-350. 2008.

MILLS, D. A. et al. Genomic analysis of Oenococcus oeni PSU-1 and its relevance to winemaking. FEMS Microbiology Reviews, v. 29, n. 3, p. 465-475, ago. 2005.

MOREIRA, N. et al. Alcohols, esters and heavy sulphur compounds production by pure and mixed cultures of apiculate wine yeasts. Int J Food Microbiol, v. 103, n. 3, p. 285-294, set. 2005.

Heavy sulphur compounds, higher alcohols and esters production profile of Hanseniaspora uvarum and Hanseniaspora guilliermondii grown as pure and mixed cultures in grape must. Int J Food Microbiol v. 124, n. 3, p. 231-238, jun. 2008.

MUÑ ZZ, R. et al. Multilocus sequence typing of oenological Saccharomyces cerevisiae strains. Food Microbiol, v. 26, p. 841-846, 2009.

NADRA, M. C. M. et al. Protease activity of Oenococcus oeni viable cells on red wine nitrogenous macromolecular fraction in presence of SO2 and ethanol. Food Control, v. 16, p. 851-854, 2005.

Evidência, Joaçaba v. 8 n. 1-2, p. 57-84, janeiro/dezembro 2008 
Culturas iniciadoras de fermentação em vinhos

NANNELLI, F. et al. Determination of lactic acid bacteria producing biogenic amines in wine by quantitative PCR methods. Lett Appl Microbiol, v. 47, p. 594 599, 2008.

NAUMOV, G. I. New Wine Yeasts: On the Publication of the Book Sovremennye preparativnye formy drozhzhey dlya vinodeliya (Modern Preparative Forms of Yeasts for Wine-making) by N.N. Martynenko, Moscow: Rossel'khozizdat, 2006. Microbiology, v. 78, n. 4, p. 520 521, 2009.

NEELEY, E.T.; PHISTER, T. G.; MILLS, D.A. Differential Real-Time PCR Assay for Enumeration of Lactic Acid Bacteria in Wine. Appl Environ Microbiol, v. 71, n. 12, p. 8954-8957, dec. 2005.

NEHME, N.; MATHIEU, F.; TAILLANDIER, P. Quantitative study of interactions between Saccharomyces cerevisiae and Oenococcus oeni strains. J Ind Microbiol Biotechnol, v. 35, p. 685693, 2008.

OLGUÍN, N., BORDONS, A. e REGUANT, C. Influence of ethanol and pH on the gene expression of the citrate pathway in Oenococcus oeni. Food Microbiol, v. 26, n. 2, p. 197-203, apr. 2009.

OSBORNE, J. P.; EDWARDS, C. G. Inhibition of malolactic fermentation by a peptide produced by Saccharomyces cerevisiae during alcoholic fermentation. Int J Food Microbiol v. 118, n. 1, p. 27-34, aug. 2007.

OSBORNE, J. P., MORNEAU, A. D.; ORDUNAA, R.M. Degradation of free and sulfur-dioxidebound acetaldehyde by malolactic lactic acid bacteria in white wine. J Appl Microbiol, v. 101, p. 474-479, 2006.

PAPATHANASIOU, I. et al. Winemaking ability of wild yeast strains and comparative volatile profiles of wines fermented at $12^{\circ}$ or $20^{\circ}$ C. Food Sci Technol Res, v. 12, n. 3, p. 194-198, 2006.

PÉREZ-NEVADO, F. et al. Cellular death of two non-Saccharomyces wine-related yeasts during mixed fermentations with Saccharomyces cerevisiae. Int J Food Microbiol, v. 108, p. 336-345, 2006.

PÉREZ-SERRADILLA, J. A.; CASTRO, M. D. L. Role of lees in wine production: A review. Food Chem v.111, p. 447-456, 2008. 
Débora dos Santos, Jane Mary Lafayette Neves Gelinski

PÉREZ-TORRADO, R., BRUNO-BÁRCENA, J.M. e MATALLANA, E. Monitoring StressRelated Genes during the Process of Biomass Propagation of Saccharomyces cerevisiae Strains Used for Wine Making. Appl Environ Microbiol v.71, n.11, p. 6831-6837, jul. 2005.

PIZARRO, F. J. et al. Growth Temperature Exerts Differential Physiological and Transcriptional Responses in Laboratory and Wine Strains of Saccharomyces cerevisiae. Appl Environ Microbiol, v. 74 , n. 20 , p. 6358-6368, oct. 2008.

POZO-BAYÓN, M. A.; ANDÚJAR-ORTIZ, I.; MORENO-ARRIBAS, M. V. Scientific evidences beyond the application of inactive dry yeast preparations in winemaking. Food Res Int, v. 42, p. 754-761, 2009.

PULVIRENTI, A. et al. Optimizing the selection process of yeast starter cultures by preselecting strains dominating spontaneous fermentations. Can J Microbiol, v. 55, p. 326-332, 2009.

QUIRÓS, C. et al. Quantitative Approach to Determining the Contribution of Viable-butNonculturable Subpopulations to Malolactic Fermentation Processes. Appl Environ Microbiol, v. 75, n. 9, p. 2977-2981, may. 2009.

RAMÍREZ, R. ; AMBRONA, J. Construction of Sterile ime1 $\Delta$-Transgenic Saccharomyces cerevisiae Wine Yeasts Unable To Disseminate in Nature. Appl Environ Microbiol, v. 74, n. 7, p. 2129-2134, apr. 2008.

RAY, B. Fundamental Food Microbiol. CRCPress, p. 173-181, 2004.

REGUANT, C. et al. Population dynamics of Oenococcus oeni strains in a new winery and the effect of SO2 and yeast strain. FEMS Microbiology Letters, v. 246, p. 111-117, 2005.

RENOUF, V. et al. Lactic acid bacteria evolution during winemaking:Use of rpoB gene as a target for PCR-DGGE analysis. Food Microbiol, v. 23, p. 136-145, 2006.

RODRIGUEZ, S. B. THORNTON, R.J. Use of flow cytometry with fluorescent antibodies in real-time monitoring of simultaneously inoculated alcoholic-malolactic fermentation of Chardonnay. Lett Appl Microbiol, v. 46, p. 38 42, 2008.

ROJO-BEZARES, B. et al. Coculture-inducible bacteriocin activity of Lactobacillus plantarum strain J23 isolated from grape must. Food Microbiol, v. 24, p. 482-491, 2007a.

Evidência, Joaçaba v. 8 n. 1-2, p. 57-84, janeiro/dezembro 2008 
Antimicrobial activity of nisin against Oenococcus oeni and other wine bacteria. Int J

Food Microbiol, v. 116 p. 32-36, 2007b.

ROMERO, S. V. et al. Potential formation of ethyl carbamate in simulated wine inoculated with Oenococcus oeni and Lactobacillus plantarum. International Journal of Food Science and Technology, v. 44, p. 1206-1213, 2009.

ROSSOUW, D. et al. Comparative Transcriptomic Approach To Investigate Differences in Wine Yeast Physiology and Metabolism during Fermentation. Appl Environ Microbiol, v. 75, n. 20, p. 6600-6612, oct. 2009.

SPANO, G.; MASSA, S. Environmental Stress Response in Wine Lactic Acid Bacteria: Beyond Bacillus subtilis. Crit Rev Microbiol, v. 32, p. 77-86, 2006.

SUMBY, K. M. et al. Cloning and Characterization of an Intracellular Esterase from the WineAssociated Lactic Acid Bacterium Oenococcus oeni. Appl Environ Microbiol, v. 75, n .21, p. 6729-6735, nov. 2009.

TABERA, L.; MUÑOZ, R. e GONZALEZ, R. Deletion of BCY1 from the Saccharomyces cerevisiae Genome Is Semidominant and Induces Autolytic Phenotypes Suitable for Improvement of Sparkling Wines. Appl Environ Microbiol, v. 72, n. 4, p. 2351-2358, 2006.

TEIXEIRA, M. C. et al. Genome-Wide Identification of Saccharomyces cerevisiae Genes Required for Maximal Tolerance to Ethanol. Appl Environ Microbiol, v.75, n.18, p. 5761-5772, sept, 2009.

TERRADE, N. et al. A new chemically defined medium for wine lactic acid bacteria. Food Res Int, v. 42, p. 363-367, 2009.

TERRADE, N.; ORDUÑA, R.M. Determination of the essential nutrient requirements of winerelated bacteria from the genera Oenococcus and Lactobacillus. Int J Food Microbiol, v. 133, p. $8-13 ; 2009$.

. Impact of winemaking practices on arginine and citrulline metabolism during and after malolactic fermentation. J Appl Microbiol, v. 101, p. 406-411, 2006.

TORRENS, J. et al. Different commercial yeast strains affecting the volatile and sensory profile of cava base wine. Int J Food Microbiol, v. 124, p. 48-57. 2008.

Evidência, Joaçaba v. 8 n. 1-2, p. 57-84, janeiro/dezembro 2008 
Débora dos Santos, Jane Mary Lafayette Neves Gelinski

TRONCHONI, J. et al. Differences in the glucose and fructose consumption profiles in diverse Saccharomyces wine species and their hybrids during grape juice fermentation. Int J Food

Microbiol, v.134, p. 237-243, 2009.

UTHURRY, C. A. et al. Ethyl carbamate production by selected yeasts and lactic acid bacteria in red wine. Food Chem, v. 94, p. 262-270, 2006.

WALLING, E.; GINDREAU, E. LONVAUD-FUNEL, A. A putative glucan synthase gene dps detected in exopolysaccharide-producing Pediococcus damnosus and Oenococcus oeni strains isolated from wine and cider. Int J Food Microbiol, v. 98, p. 53-62, 2005.

WEIGERT, C. et al. Application of a Short Intracellular pH Method to Flow Cytometry for Determining Saccharomyces cerevisiae Vitality. Appl Environ Microbiol, v. 75, n. 17, p. 5615-5620, sept. 2009.

VERSARI, A.; PARPINELLO, G. P. e CATTANEO, M. Leoconostoc oenos and malolactic fermentation in wine: a review. J Ind Microbiol Biotechnol, v. 23, p. 447 455, 1999.

VIANA, F. et al. Rational selection of non-Saccharomyces wine yeasts for mixed starters based on ester formation and enological traits. Food Microbiol, v. 25, n. 6, p. 778-785, set. 2008.

. Increasing the levels of 2-phenylethyl acetate in wine through the use of a mixed culture of Hanseniaspora osmophila and Saccharomyces cerevisiae. Int J Food Microbiol, v. 135, p. 68-74, 2009.

ZAPPAROLI, G. et al. Bacterial inoculation strategies for the achievement of Malolactic fermentation in high-alcohol wines. South African Journal of Enology and Viticulture, v. 30, n. 1, p. 49-55, 2009.

ZHAO, W-Y. et al. The Effect of Acid Stress Treatment on Viability and Membrane Fatty Acid Composition of Oenococcus oeni SD-2a. Agricultural Sciences in China, v. 8, n. 3, p. 311- 316, mar. 2009.

ZUZUARREGUI, A. et al. Transcriptomic and Proteomic Approach for Understanding the Molecular Basis of Adaptation of Saccharomyces cerevisiae to Wine Fermentation. Appl Environ Microbiol, v. 72, n. 1, p. 836-847. 2006.

Evidência, Joaçaba v. 8 n. 1-2, p. 57-84, janeiro/dezembro 2008 
Culturas iniciadoras de fermentação em vinhos

Recebido em 25 de outubro de 2010

Aceito em 10 de março de 2011

Evidência, Joaçaba v. 8 n. 1-2, p. 57-84, janeiro/dezembro 2008 
